\title{
Dinoprost Tromethamine
}

National Cancer Institute

\section{Source}

National Cancer Institute. Dinoprost Tromethamine. NCI Thesaurus. Code C1074.

A synthetic analogue of the naturally occurring prostaglandin F2 alpha. Prostaglandin F2

alpha stimulates myometrial activity, relaxes the cervix, inhibits corpus luteal

steroidogenesis, and induces luteolysis by direct action on the corpus luteum. (NCI04) 